\title{
Worker Expertise and New Worlds of HCI: Implications of Sociotechnical Systems Design
}

\author{
Bruce Wilson, \\ Union Research Centre on Organisations and Technology, \\ Australia.
}

Over the last 40 years, Socio-Technical Systems Design (STSD) has provided extensive insights into the relationships between the technical and social processes in workplaces. Although STSD has been used most commonly in manufacturing environments, it has much to offer also in workplaces dependent on computers, especially as more complex forms of information technology become more prevalent in workplace life.

This paper presents a case study of the work of the Union Research Centre on
Organisations and Technology (URCOT) which has drawn on Scandinavian experience with STSD to develop an applied participative approach which enables worker expertise to be contributed effectively in large-scale organisational and technological change projects. Some background to the formation of the Centre, the nature of the work being undertaken and its benefits will be provided, before concluding with an examination of the implications of URCOT's work for the 'new worlds' of HCI. 